\title{
Temporal Aspects of Literary Reading
}

\author{
David S. Miall
}

\begin{abstract}
One of the prominent features of literary reading is a sense of defamiliarization: a passage describing an object, event, or person in the mundane world unexpectedly seems strange, so that the reader is made to pause or slow the pace of reading in order to reflect. In Owen Barfield's words, such moments seem to come from "a different plane or mode of consciousness" (Poetic diction: a study in meaning. McGraw-Hill, New York, 1964, p. 171), and they demonstrate the "unfamiliar" of the artwork discussed by Shklovsky (Art as technique. In: Russian formalist criticism: four essays, eds. and trans. Lemon LT, Reis MJ. University of Nebraska Press, Lincoln, 1965, p. 12). I identify several mental processes that help constitute the sense of strangeness and that may contribute distinctive elements to the presence of literariness. I examine the initial moments of the experience of literary reading, those occurring in the first few hundred milliseconds as suggested by studies of EEG waves: these include absence of habituation, the deferral of intention, the thwarting of prototypical feeling, bodily alertness, and the experience of animacy. I then consider some sequential features that guide and shape response on a larger scale, focusing in particular on the processes of feeling and their impact on the reader.
\end{abstract}

Keywords Literature • Defamiliarization • Reader • Electroencephalography • Feeling

\section{Introduction}

Literary readers are in the strange position that they do not necessarily understand what it is they are reading; yet the text may impel them to pause, perhaps momentarily, to reflect on what they have just read, or it spurs them to read on with the prospect of clarification to come. Shklovsky's well-known comment that

D.S. Miall $(\bowtie)$

Department of English \& Film Studies, University of Alberta, Edmonton, AB, Canada

e-mail: David.Miall@ualberta.ca 
art should prolong our experience of perception invokes these initial moments of strangeness, usually in response to foregrounding (unusual stylistic features). $\mathrm{He}$ argues that literature is a different kind of experience from other verbal effects:

The technique of art is to make objects 'unfamiliar,' to make forms difficult, to increase the difficulty and length of perception because the process of perception is an aesthetic end in itself and must be prolonged. (1917/1965, p. 12)

This sense of defamiliarization and consequent difficulty is often mentioned. For example, Owen Barfield (1964) suggests the "interior significance" of defamiliarization "must be felt as arising from a different plane or mode of consciousness" (pp. 170-171).

Here, then, we have an impression of literariness, that is, how the literary experience is distinctive. But how is this achieved? What is occurring in those first moments of response to the literary artifact? What are its formal or stylistic fingerprints? We have very little direct evidence on this issue. For the most part, attempts to understand what is occurring must draw upon less direct evidence-on guesswork or speculation. In this contribution, I can only offer a brief sketch of some of the possible components of literariness.

That readers find literary narratives strange at times and express their sense of defamiliarization is shown by one of our earlier studies (Miall and Kuiken 1999) the narrative in question here was “The Trout” by Seán O'Faoláin (1980). The story was divided into 84 short segments, mostly one sentence in length, and presented on computer screen cumulatively, one segment adding to previous segments. Readers paced themselves through the story by pressing the space bar to reveal the next segment.

In generating comments on the story as part of a think-aloud study, we found that among the different types of comment it was the frequencies of associations, comments on style, and queries that most strongly predicted reading times (we collected reading times data per segment during a parallel study). Associations, for example, correlated highly with reading times, $\mathrm{r}=.402, \mathrm{p}<.001$; queries were significant at the same level, $\mathrm{r}=.438, \mathrm{p}<.001$, as were comments on style, $\mathrm{r}=.387$, $\mathrm{p}<.001$. In these and other ways, readers showed a sensitivity to several dimensions of the literariness they were encountering-elaborating their understanding of settings or actions, appreciating literary devices, or expressing their queries about the meaning of various passages. In fact, queries were the third most frequent type of comment at $10.1 \%$, following character explanation at $33.6 \%$ and quotations at $21.5 \%$ (132). Quotations correlated highly with foregrounding in the story, $r=.463$, $\mathrm{p}<.001$, suggesting that readers found the passages they quoted unfamiliar and challenging, hence the need to repeat the passage aloud.

But what makes such passages distinctive, calling for the additional depth of attention indicated by lengthened reading times? There can be no one feature responsible for such experiences of literariness: in what follows I will mention several possible features that may be responsible for that experience of strangeness. I will refer in particular to events that, in the light of several (non-literary) 
EEG studies, can be postulated as occurring very early in the reader's train of response, at moments half a second or less following an encounter with the unusual linguistic features of a foregrounded passage or a twist in our experience of the narrative.

Unlike the reading of expository prose, which elaborates and develops a model that is based on an initial organizing concept, literary reading is typically prospective, sustained by anticipations of what is to come, and slowed as we have seen by a need to engage with foregrounding, or to entertain more than one meaning for what the text at a given point or as a whole might be saying. In this context, readers may delay closure on what a text means.

As Zwaan (1993) notes, to the extent that literary texts are indeterminate or ambiguous, they are likely to invite a bottom-up mode of processing, which is typically slower than top-down (p. 148). This may also lead to a more loosely organized textbase, since more information may turn out to be relevant. As he puts it, there is evidence that "readers of stories pay special attention to details, especially when they are mentioned in isolation from other details" (pp. 149-150). Another way of putting it is that the reader forms a weak situation model and defers closing in on a coherent one that can account for all the information. Here is one apparent difference in how literary reading feels compared with reading for information. But in promoting Barfield's sense of strangeness, what makes the difference in the case of literary reading? A number of implications come to mind, but these five modes of processing in particular seem possible contenders for the creation of moments of strangeness (further research may reveal other contenders). I consider next some evidence that each may occur early in the response process, that is, prior to the 400-500 ms at which consciousness of an event occurs:

- No habituation

- Intentionality deferred

- Thwarting of prototypical feeling

- Bodily alertness underlies representation

- Animacy of events and objects.

Common to each may be a rapid processing that predisposes consciousness to generate insights from such earlier phases of response, especially the creation of new meaning (as in response to a novel metaphor).

In what follows, I refer to "The Trout" for examples of the kinds of interpretive processes implied by specific moments in the story. The story concerns Julia, a 12year-old girl, at the beginning of her vacation in the country. With her younger brother Stephen, she enjoys a pleasurable fear running through the "Dark Walk," a tunnel of old laurel hedging in her garden, where she finds a live trout in a small well. She tries to find out how it could have gotten there, including an interrogation of Old Martin the gardener, but to no avail. Eventually she gets up at night and rescues the trout, releasing it into a nearby river. 


\section{No Habituation}

Literature, as we saw, is said to enable us to see the world freshly. In his Defence of Poetry, Shelley claims that a chief effect of poetry is that it "purges from our inward sight the film of familiarity which obscures from us the wonder of our being" (1840/1988, p. 295). The question then is whether with repeated encounters with the same texts we tire of such defamiliarizing novelty and cease to experience it. In Colin Martindale's literary-historical account (1990), literary creation is shaped by the need for an increasingly defamiliarizing style; only by devising ever more vivid and unusual stylistic effects can a poet retain an audience. For example, Keats exceeds Wordsworth in stylistic innovation; Tennyson exceeds Keats; and Swinburn exceeds Tennyson. Yet we continue to read Shakespeare, Wordsworth, or Keats with pleasure and, as the years go by, perhaps even greater insight. One explanation lies in our first responses to detecting evidence of emotion.

In the case of pictures that evoke emotion, it has been found (Schupp et al. 2006) that virtually no habituation takes place: responses occurring within a 150 $300 \mathrm{~ms}$ window remain almost as strong after repeated exposure as the first time (pictures used were of erotic, neutral, and mutilation themes). The study focused on the differences in rapidly processing pleasant and unpleasant pictures compared with neutral pictures. As measured by EEG, differences were shown by a larger early posterior negativity (EPN): a highly significant main effect due to emotion (compared with neutral pictures) was shown over temporo-occipital and frontocentral sites, beginning around $160 \mathrm{~ms}$ following exposure of the picture and being most pronounced in the 200-300 ms time window. The authors suggest that "the detection of emotionally significant stimuli in the environment is an obligatory task of perception, evincing little evidence for habituation as a function of passive stimulus experience" (p. 368). As the implication of these findings most likely extends to literary reading, where response to single words or sounds is obligatory, it seems we are designed always to react, in Irving Massey's words, to "the unquenchable freshness" of the words (2009, p. 89).

While the study of Schupp et al. (2006) shows evidence of dehabituation (as we will call it) occurring as early as around $200 \mathrm{~ms}$, this is dependent on rapid and frequent exposure of emotional pictures. How far is this likely to illuminate the reader's response to literature? Prompts to feeling occur at the stylistic level of much literary language: most obviously we find repeated phonemes (alliteration, assonance) often deployed to underline the intensity of a mood conveyed by description of a setting or the predicament of a character. For example, in "The Trout," after running through the Dark Walk, Julia "emerged gasping, clasping her hands, laughing, drinking in the sun." This exhibits in close proximity three long /a/ sounds, five /ing/ sounds, and several other features that illustrate at the level of sound Julia's half-fearful excitement which, as it is read, helps create and sustain the same emotion in the reader. In the light of the Schupp et al. study, no habituation is occurring while these repeated phonemes are encountered. Moreover, such repeated phonemes suggest their own meanings, underlying the overt verbal meaning of the 
text. The long /a/ sound seems to connote exhalation, relief. While phonemes do not have a fixed meaning (Miall 2001), they take on a local significance determined in part by the immediate context, contributing to the array of meanings activated for the reader during this moment of reading.

Other neuropsychological studies of habituation indicate that it is negative emotional experience that is most likely to show resistance to habituation. In an ERP study, Carretié et al. (2003) showed that negative emotional pictures were more resistant to habituation than positive or neutral pictures. They indicate that this provides an example of the negativity bias, that is, a more rapid and intense response that occurs to aversive events. The EEG component that was the object of this study was the N1 (a negative wave peaking at $100 \mathrm{~ms}$ ), which has been found to be an indicator of level of attention; thus, higher attention signifies lower habituation. As the authors put it, "analyses of N1 indicate that the highest resistance to attentional habituation is specifically produced in response to S- [negative pictures]." While this study used pictures, previous studies suggest that N1 is not limited to visuospatial attention (Wang et al. 2008).

Another study, by Marchewka and Nowicka (2007), looked at the concept of priming, which also implies a measure of habituation. In a series of presentations, such as pictures, where each picture is the same or similar to the preceding one, the later presentations can be regarded as primed, that is, expected, by the previous ones. Participants were required to respond to a verbal or visual stimulus while their reaction time (RT) was measured. When neutral words or images were shown, repeated presentations showed the effect of priming (participants had become used to this kind of stimulus), and RTs became shorter. When presentations were emotionally negative (fearful faces were used), no effect of priming was found; RTs remained at the same level. It was also found that new negative stimuli (images or words) were detected significantly faster than new neutral stimuli (p. 87). Overall, no effect of priming was seen for emotionally negative stimuli, and this result occurred whether presentation was to right or left hemisphere-although the right is said to be specialized for responses to emotionally negative materials (p. 88). The study can be said to demonstrate the adaptive value of a fast response to negative events, which most likely had a high survival significance in the ancestral environment. Thus it would also be significant that the response to negative events is not attenuated with repeated presentation. The authors point out that no conscious control is exercised over the response: "Automatic stimulus evaluation is a very fast process and occurs at a very early stage of information processing." It is, in other words, another response occurring prior to the threshold of consciousness (set at around 400-500 ms). Each word of Julia's half-fearful "gasping, clasping [...] laughing" will be experienced by the reader with a similar force, a similar degree of dehabituation, thus helping to develop that slight sense of Gothic threat that a number of our readers have noticed.

A comparable finding in music, although one not dependent on millisecond timing, is reported by John Sloboda (1991). Sloboda studied the occurrence of emotional and bodily responses to music, such as tears, shivers, or racing heart. Participants reported such feelings to be quite reliably experienced in relation to 
particular pieces of music, often a specific phrase or theme; and this held even when they had listened to the same piece 50 or more times: "Clearly," Sloboda comments, "listening to a piece of music very many times does not always entail a diminishing of strong emotional response to it" (p. 113).

This freshness of emotion may persist as a part of the ensuing emotional experience, as though the emotion lacked temporal markers. As Coleridge put it, "All intense passions have faith in their own eternity" (1957-2002, III, p. 4,056).

\section{Intentionality Deferred}

When accounting for our stance as readers towards literary characters, an important part will be played by the attribution of intention to a character. Since intentions cannot always be inferred automatically from actions or dialogue, intentions may be ambivalent. Old Martin reaches for the trout when it is pointed out to him. Is this because he intends to rescue and release it or because he would like it cooked for supper? And what does Julia intend by forcing Old Martin to leave the trout where it is? Studies of mirror neurons in humans suggest that an observer will simulate the initial pre-motor and motor phases of this action while inhibiting its execution, whether based on visual, sensory, or verbal stimuli (and in the case of humans, a goal for the action is not obligatory; "intransitive" movements may also stimulate a response: Gallese et al. [2004, p. 397]). Thus a reader will acquire a sense of the intentionality inherent in the behavior and comments of both Julia and Old Martinan array of intentions or the absence of intention that will contribute to the situation model being constructed by the reader. This represents the straightforward account. In its early phases, however, we may witness a somewhat divergent situation. I mention three example studies below that tend to complicate the issue.

First, the early phases may be marked by an attribution issue. The standard mirror neuron account, as far as it concerns the first several hundred milliseconds, is questioned by an analysis of Becchio and Bertone (2005). At the early phases of response (prior to $500 \mathrm{~ms}$ ), intention is not unambiguously present; later (after the elapse of a second or so), intention may be assigned through sympathy or empathy for a character that establishes intentions and goals, or intention may be assigned to a narrator. Following analysis of mirror neuron systems, Becchio and Bertone (2005) remark:

When observing other people acting, the activation of shared neural representation allows
us an immediate access to their motor intention. Given the existence of a neural substratum
shared between the self and the other, the problem of the other, we argue, is reversed in its
own presuppositions: the problem is no longer 'how is it possible for part of the I-experience
to refer to others?' but rather 'how one can distinguish one's own action/intention from
those of other people?' (p. 21)

Or, as Jeannerod and Pacherie (2004) have shown, "We can be aware of an intention, without by the same token being aware of whose intention it is" (p. 140). 
This issue over intentionality contributes to literariness in so far as it is developed by, for example, the uncertainty, ambiguity, or conflict of intentions of a character, as in the exchange of Old Martin and Julia, or by the unreliability of a narrator (Miall 2012). We might assume, also, that an inability to attribute intention that implicates one or more characters, the narrator, or the reader may at times create, albeit momentarily, that sense of shared significance, of community, which we experience as literary readers. The mirror system, under favorable circumstances, may eliminate the wall of solitude that separates two consciousnesses, even though one is present merely as words on a page (see Keen [2006] for an account of empathy in literary reading and mirror neurons).

Second, a study of response to faces raises the possibility of an absence of intentionality over the first few hundred milliseconds under certain conditions; I will raise the question whether this is likely to generalize to literary response. In a study by Rellecke et al. (2012), intention on the part of the viewer was absent when viewers processed an angry face compared to processing a neutral or a happy face. As shown by ERP visual components P1, N170, and EPN (early posterior negativity)_ERP components that have been implicated in face and emotion response-early processing of negative stimuli occurred without intention, that is, unaffected by one or other of several simple tasks required of participants in response to the faces. These included passive viewing, or judging the emotional expression of a face, or stating whether the presentation is of a picture or a word. Positive (happy) and neutral faces, on the contrary, showed the influence of intention. The authors conclude that two different kinds of processing are occurring: "an automatic threat-related processing bias at perceptual stages, while higher cognitive emotion encoding is subject to voluntary control" (p. 23).

While the authors consider only one negative emotion-anger-in their study, the findings are suggestive. They show that such an emotion cannot in its first moments be controlled or modified by any intentional perspective, that intention is suspended or absent. In this respect, it indicates that a new, unassimilated experience is occurring, one that will call for attention. For example, here is one occasion when Julia demonstrates anger: interrupting her mother's tale of how the trout came into its hole, "Passionately she had whirled and cried, 'Mummy, don't make it a horrible old moral story!", That her response is characterized as passionate suggests an involuntary excess of angry emotion; in that it is unwilled it can be regarded as a contribution to Julia's increasing sense of emancipation from the parental ward, a growth in her being that is at first unattributed. It is not, in other words, a negotiated state, but one basic to her transition to the state of womanhood. It will conclude with her bold rescue and release of the trout at the end of the story. Anger may be only one of several basic, negative emotions that run off initially like anger without the influence of intention, in that for the system experiencing them the emotion process is obligatory. This seems essential with fear and likely to be the case with disgust. In this way, the system is signaling that the emotion preempts any other cognitive or emotional process currently in train and must be given undivided attention.

The third example I will describe stems from well known studies by Libet et al. (1983), studies of the moment of choice that appear to cast doubt on our 
possession of freewill. A recent study by Rigoni et al. (2010) focused on evidence for unconscious preparation for action, the Readiness Potential, shown by EEG measures occurring from $500 \mathrm{~ms}$ up to $1,000 \mathrm{~ms}$ (a slow negative-going potential) prior to action. Thus preparation to act was shown to occur in the brain some 300 $800 \mathrm{~ms}$ before participants reported a conscious decision to act. Explicit intention to act is said to be attributed retrospectively, and to occur only about $200 \mathrm{~ms}$ ahead of action. Hence, the Readiness Potential can be considered preparation for any possible action, but one that gives a spurious sense of freewill, as though the action had been freely chosen. The findings of this study are replicated in a number of other studies, with

evidence suggesting that the sense of volition is not a driving force in the initiation of our behavior. Rather, it seems that the subjective experience of free will is a construction, derived from the brain's motor system producing a movement and somehow 'informing' consciousness of the movement, with the effect that we feel as if the action has been freely chosen. (p. 2)

Action thus only appears to coincide with intention retrospectively.

The study asked participants to press a button and report when they formed the intention of pressing the button. The button press was supposed to coincide with auditory feedback (a computer emitted a $200 \mathrm{~ms}$ beep), but feedback was systematically delayed by a number of milliseconds, varying randomly between 5, 20, 40, or $60 \mathrm{msec}$. Findings showed that the later the feedback, the more the report of the participant shifted to a corresponding later moment. This suggests that the experience of the moment of choosing to act is an artifact that in some way the brain has unconsciously already made a decision to act, so that our awareness of choosing is belated. (For a critique of these studies of Readiness Potential and freewill and some alternative construals, see Ellis [2005, pp. 144-146]).

Statements of intention and fulfillment of intention are very frequent in literary stories. The opening sentence of "The Trout" conveys the implicit intentions of Julia as she and her family arrive. "One of the first places Julia always ran to [... was the Dark Walk." She wants the frightening experience of running through its dark tunnel and out again into the sun. Questions to consider are whether Julia's intentions are realized and, if so, does she recognize them only as they are fulfilled; or if at certain moments when she acts or responds, she has no intentions, only behaviors. Her behavior running through the Dark Walk in the opening sentences of the story appears to repeat a favorite activity, but the odd evocation of memory and the tone of fright with which it is described argues that her running ostensibly connotes a new experience that she claims only after its completion (she and the younger brother who also runs behind her "came back to the house to tell everybody that they had done it"). What appears to occur, shown by Julia's screams of pleasure, is that she is setting herself a challenge that will in time develop her personality in ways that are hinted as the story progresses. The activity seems childish, but in fact it tests her mettle, her determination, her ability to face an ordeal. But these are implicit meanings: if they are intended, it is her character, not her conscious self, that instantiates them. She is the instrument that carries them out. I am assuming 
here that the Libet-type study, which concerns motor intentionality, can be scaled up to capture the kind of more global intentionality that Julia demonstrates. How far this capacity can be shown in the case of literary readers will require further research.

Another sentence early in the story helps set the paradigm for belated intention that occurs elsewhere in the story. At the beginning of her run, "For the first few yards, she always had the memory of the sun behind her." Note that the first phrase is empty, a merely temporal expression appearing to connote the time taken to run a certain distance. Yet her experience of this as a period of time is immediately cancelled by the term "always," evoking a presence in her memory much more significant than the running itself. In sum, the author uses the experience of late attribution of intention almost as though it is this that pulls Julia into transcending her childish phase and constructing her own maturity. An effective example of this process is this sentence, a page further on, after being asked if she saw the well: "She opened her eyes at that and held up her long lovely neck suspiciously and decided to be incredulous." Here it is the body that holds open a space for intention (her eyes, her neck), until an explicit claim to intention (being incredulous) is made. It is striking that Julia's primary intention, to rescue the trout, is not made evident until the last quarter of the story.

\section{Thwarting of Prototypical Feeling}

As Greg Smith (2003) puts it, prototypical emotions are generally seen as objectoriented, intentional, directed at something, and including an action tendency (p. 21). Whatever we are reading (including non-literary texts), the system may recognize early on that an emotion is apparent and situate it in relation to whichever prototypical emotion it prompts; such an emotion (for example, pity, anger, joy) will run off without hindrance and create an unequivocal emotional situation, one that the reader will recognize as familiar and through which she will shape her expectations about how the text will continue. Here, for instance, is part of a paragraph from an article in The Guardian about the surveillance carried out by the British spy agency, GCHQ, and whether it is necessary (Lanchester 2013):

We do have enemies, though, enemies who are in deadly earnest; enemies who wish you reading this dead, whoever you are, for no other reason than that you belong to a society like this one. We have enemies who are seeking to break into our governments' computers, with the potential to destroy our infrastructure and, literally, make the lights go out [...]

We readily identify the main emotion in question in the first sentence here: fear. The text continues by elaborating and justifying this claim, giving reasons: our enemies are breaking into important computers; the lights may go out; and so the article continues, offering additional reasons for feeling fear, and redirecting the cause of fear onto the spy agencies themselves. The prototypical nature of the fear in question throughout the article is not questioned. 
In literary reading, however, the text may thwart the systematic development of the emotion in relation to this first situation-perhaps through conflicting phonetic patterns or an ambiguous reference to a character; or the action suggested may become other than what was first implied by the prototypical emotion. In this way, a literary passage can shift the reader's attitudes and inclinations away from what first seemed in question to a prospect that is unfamiliar and challenging. An action plan is still in evidence, but it may propose ends that we have trouble recognizing (hence perhaps the "fresh emotions" shown in Cupchik et al. 1998), or ends that we now find aversive. Such emotions can be powerful: they may call into question interpretive processes already underway, such as the markers of aesthetic structure that we create to orient ourselves to the text, the breakdown of monovalent understanding into a multivalent one, or our empathic regard for the protagonist in the narrative.

In "The Trout," we seem to be offered an experience of fear halfway through the story as Julia jumps out of bed at night: "somehow it was not so lightsome now" with the prospect of "dim mountains," "black firs," and the barking of a dog. But it seems that Julia does not hesitate and the initial fear transitions to include Julia's boldness, her courage in navigating the nighttime visit to the Dark Walk (another mark of her maturing), and then extends to the situation overall as she finds the trout - she cries aloud, she is "mad with fright" along with the trout, but she is still courageous, "her teeth ground." And in this passage phonetic coloration provides a third emotional perspective to be experienced alongside the fear and the courage: the main terms "dim mountains," "black firs," and "bark-bark" have a presence to them given by their adjacent strong stresses that sets them down like the pillars of a temple. Another supporting sound structure is "the cool but cruel gravel" that helps animate the setting, underscoring what Julia must contend with as she approaches the Dark Walk and its inhabitant. In terms of the aesthetic frame of the story, it is notable how this moment of rescue sees Julia again racing through the tunnel, a fearful complement to racing through the dark for the pleasure of terrifying herself that opens the story.

\section{Bodily Alertness Underlies Representation}

As Kuijpers and Miall (2011) showed, bodily responses seem to occur systematically while reading a literary text. In their study, participants reported when they experienced a bodily sensation while reading a modernist short story, describing how it felt and marking its location on a diagram of the human body. One important finding was that the frequency of bodily responses to specific passages in the story correlated significantly with the occurrence of foregrounding in the passages being read. It seems probable that bodily responses of this kind are elusive and hard to recognize, and difficult to capture empirically. However, they can also be found at times in the descriptions of novelists; this would make an interesting study in itself. 
For example, striking examples of bodily responses that create an aesthetic experience can be seen in Virginia Woolf's novel The Years (1937/2009). Here we watch Martin walking across London and arriving opposite St. Paul's Cathedral. "He crossed over and stood with his back against a shop window looking up at the great dome. All the weights in his body seemed to shift. He had a curious sense of something moving in his body in harmony with the building; it righted itself: it came to a full stop. It was exciting - this change of proportion" (p. 216). Here is evidence of the active role of the body in shaping an aesthetic experience-a process of which Martin is conscious, but this is not necessary; much that we perceive or experience occurs below the level of consciousness yet still exerts some influence on subsequent attention and processing: "Unattended objects [...] may still be processed to fairly high levels, and the processing itself may summon attention" (Posner and DiGirolamo 2000, p. 882).

We don't often think of the mind as influenced by the body, but this was one of the major insights of the poet Wordsworth. This is elaborated in a number of places in Wordsworth's early writing. For example, in 1799, while sketching early drafts of what was to become his great autobiographical poem The Prelude, he refers to bodily shaping and realization of mind, how sensations internal and external provide materials out of which the mind is created. Thus he claims a sensibility "quickened" by emotion, where "all my thoughts / Were steeped in feeling" (1799, II, 447-448), showing how early experience, as Richardson (2001) notes, "implies a mind shaped by and realized in bodily organs, though not entirely defined by them" (p. 71). In his response to nature, images are "Felt in the blood, and felt along the heart" ("Tintern Abbey," p. 29, in Gill 2000)_images that persist and help shape the mind:

By force

Of obscure feelings representative

Of joys that were forgotten, these same scenes ...

Become habitually dear, and all

Their hues and forms were by invisible links

Allied to the affections. (Wordsworth 1799, I, 435-442)

Thus the literary power of a text, in a similar way, may enforce itself upon the reader's body, forging "invisible links" that shape response for years to come.

\section{Animacy of Events and Objects}

It has often been remarked (e.g., Coleridge 1983, I, p. 9) that not a word can be missed from a literary text; we commonly respond as though all words and sentences are relevant, although during an initial reading it may be too soon to judge if this is the case. Yet we endow objects and events with the gloss of final significance, such that whatever is said, done, seen, felt, etc., while reading is considered to contribute somehow to the total aesthetic experience and meaning of the text. This assumption underlies what I will call animacy tracking: if all is relevant, then each 
separate mention embodies a relationship to the overall meaning. Supposing a tree is described: then the tree must be inherently implicated in the unfolding feelings and perceptions of the narrative and that is why the description of it has been included by the writer. This is exemplified by the "pathetic fallacy" to which Ruskin objected (1897, III, pp. 161-177) — the attribution of human emotions to objects in nature so that they participate in forwarding the narrative drama that is infolding. (One feels that Snoopy in the Peanuts cartoon is about to commit this fallacy when he begins his novel: "It was a dark and stormy night.") To produce, on the contrary, a sense of the ordinariness, the randomness of events and objects is actually nearly impossible. And as many writers have observed, animacy is the default assumption when a questionable object in the environment attracts attention. This enlivenment of the verbal may extend to objects that we read about in the first few hundred milliseconds of response. The sense of other presences, of dimly sensed consciousnesses, may then continue to animate the ensuing narrative. As Wordsworth put it, in a fragment of verse: "There is an active principle alive in all things" (Wordsworth 1979, p. 676).

Julia evidently feels some affinity with this power in nature: she is aware of the landscape beyond her bedroom window, as the poetic description of it suggests: "the dim mountains far away and the black firs against the breathing land." Yet this does not dissuade her from getting up and going outside, where she becomes an active agent herself in the animate world of the trout. Here too as she releases the trout we find animation in how "the moon-mice on the water crept into her feet."

My comment here around the Wordsworth passage is speculative, but it is in accord with what we are coming to know about embodied cognition and the role and powers of feeling in particular, what Ellis (2005) describes as the "intentionality of feelings — what they are 'about' — [which] includes aims as well as environmental affordances and triggering objects" (p. 6). Although literary response articulates these premises, they have been little studied until now with serious attention to the bodily correlates of reading. Here, as Mark Johnson (2007) puts it, "immanent bodily meaning is paramount" (p. 209).

\section{Sequence Issues}

Given the five processes I have just reviewed, it remains for us to see how they can be placed within a functioning psychological system, one that does justice to the complexities of literary response as far as possible, and one that would help account for that early sense of strangeness. Here is where questions of sequencing become important. First, what sequence is in question when we consider emotion itself?

Arguments over the place of emotion or feeling in the cognitive and bodily system, in particular the place and nature of appraisal, have been occurring for over a 100 years. Does appraisal, that is, realizing the meaning of an event, precede our development of feelings towards the event? Notice how, in the following description emotion is placed last in the sequence. This is David Brooks' account of emotion in his recent book The Social Animal (Brooks 2012). 
In what Brooks terms the Emotional Positioning System, or EPS, the system "senses your current situation and compares it to the vast body of data it has stored in its memory. It reaches certain judgments about whether the course you are on will produce good or bad outcomes, and then it coats each person, place, or circumstance with an emotion [...]" (pp. 501-506). This looks a plausible process, but emotion is put at the wrong end. First, an emotion occurs informed by a preliminary sense of context, situating us in relation to a future state if the emotion were extended; this possibility is then appraised, with the assistance of our autobiographical memories; finally the future situation evoked by the emotion is evaluated, i.e., judged as constituting a good or bad outcome for the self (e.g., what kind of person would I become if I gave free rein to this anger). Development of this system begins in infancy when emotional responses are learned through social referencing (Feinman 1992), as it has been called. In this situation, when infant and mother regard the same object, emotion and perception of the object or event are learned simultaneously by the infant-especially if the mother's response is a vocal one: the intrinsic acoustic properties of vocal affective expressions, such as loudness and pitch, may induce emotions directly, a phenomenon that we can also infer from the EEG studies of responses to emotion over the first 400-500 ms in language and other media.

To summarize the processes we have suggested with a view to their sequencing: The early, i.e., preconscious, occurrence of emotion during verbal response (not yet literary) may, we can suggest, be inflected by the precursors of intentionality (as in the Libet-type study) or its ambivalence, or even its absence in the case of the negative emotion; by the absence of habituation that marks the freshness of the emotion; and by experiences of animacy that will be striking if applied to objects that later (within a second or two) turn out to be inanimate (e.g., the "smooth, sinewy branches" of the Dark Walk). At the same time, response may recruit areas of the body that help shape and prolong the aesthetic sense. It is when there is a thwarting of the prototypical emotion on the cusp of consciousness (at 400-500 ms) that literary response begins to develop, as it picks up and is shaped by the implications of the sequence of phenomena-as intentionality shapes the sociality of the described moment, as alternative scenarios develop and trouble the emotion prototype, and as the body resonates to the emergent flow of awareness. Here is where the strangeness of the literary is emergent, with its complexities and ambiguities, its divergent perspectives that propose themselves to the evaluative regard of the reader.

The actual sequence of events will depend on the interaction between the text and the individual reader who brings to each moment of reading her own proclivities and experiences. For instance, in the following segment Julia is beginning her run through the Dark Walk:

then she felt the dusk closing swiftly down on her so that she screamed with pleasure and raced on to reach the light at the far end

In the opening section of the story up to this point Julia's intentions in running remain unspecified, although this is certainly the most significant piece of information that a reader requires so far. Readers will either fill this gap 
with their own concept of intention taking up whatever clues may have emerged preconsciously, or they will leave intentionality in abeyance until this segment, which supplies a first draft, as it were, of Julia's intention. This is signified by the phrase "so that," from which we learn that she "screamed with pleasure." The ambivalence of this emotion is developed by subsequent references to Julia's "ordeal," to "terrifying" her younger brother, and to their "fear." These references summon negative emotions, suggesting points in the story where habituation will not occur, thus ensuring the freshness of attention that the reader must bring to a key aspect of the story. In the present segment, we also find another hint of animacy in attributing motion to "the dusk closing swiftly down"- - an image that one reader we studied compared to "something like a blanket closing around me when I read," a bodily response that other readers may also have experienced. In addition, as we noted earlier, a description of action, which is also the case here, activates the motor and premotor neurons while inhibiting execution of the action, and this enlivens the reader's imagery of Julia's behavior.

The text continues to guide us, of course, in shaping the parameters of response. Somewhat as in social referencing (as we mentioned earlier), where the baby shares its mother's line of gaze, readers look to a narrator for simultaneous guidance on what to pay special attention to and how to feel about it (drawing on our version of this capacity as adults); in literary response, there may be more than one line to follow here-in the most dramatic examples, both acceptance and rejection, both belief and disbelief, etc. (think of The Turn of the Screw). But all normally felt experiences of literariness are likely to share these moments of emergence, the set of impulses from processes initiated and shaped preconsciously during the first few hundred milliseconds of response. Such processes, or their traces, are hard to detect-and will be difficult to study empirically.

Open Access This chapter is distributed under the terms of the Creative Commons Attribution Noncommercial License, which permits any noncommercial use, distribution, and reproduction in any medium, provided the original author(s) and source are credited.

\section{References}

Barfield, Owen. 1964. Poetic diction: A study in meaning. New York: McGraw-Hill.

Becchio, Cristina, and Cristina Bertone. 2005. Beyond Cartesian subjectivism: Neural correlates of shared intentionality. Journal of Consciousness Studies 12: 20-30.

Brooks, David. 2012. The social animal: The hidden sources of love, character, and achievement. New York: Random House.

Carretié, Luis, José Antonio Hinojosa, and Francisco Mercado. 2003. Cerebral patterns of attentional habituation to emotional visual stimuli. Psychophysiology 40: 381-388.

Coleridge, Samuel Taylor. 1817/1983. Biographia literaria, ed. James Engell and W. Jackson Bate. Princeton: Princeton University Press.

Coleridge, Samuel Taylor. 1957/2002. The notebooks, ed. Kathleen Coburn. London: Routledge \& Kegan Paul. 
Cupchik, Gerald C., Keith Oatley, and Peter Vorderer. 1998. Emotional effects of reading excerpts from short stories by James Joyce. Poetics 25: 363-377.

Ellis, Ralph D. 2005. Curious emotions: Experiencing and the creation of meaning. Amsterdam: John Benjamins.

Feinman, Saul (ed.). 1992. Social referencing and the social construction of reality in infancy. New York: Plenum Press.

Gallese, Vittorio, Christian Keysers, and Giacomo Rizzolatti. 2004. A unifying view of the basis of social cognition. Trends in Cognitive Sciences 8(9): 396-403.

Gill, Stephen (ed.). 2000. William Wordsworth: The major works. Oxford: Oxford University Press.

Jeannerod, Marc, and Elisabeth Pacherie. 2004. Agency, simulation and self-identification. Mind \& Language 19(2): 113-146.

Johnson, Mark. 2007. The meaning of the body. Chicago: University of Chicago Press.

Keen, Suzanne. 2006. A theory of narrative empathy. Narrative 14(3): 207-236.

Kuijpers, Moniek M., and David S. Miall. 2011. Bodily involvement in literary reading: An experimental study of readers' bodily experiences during reading. In De stralende lezer: Wetenschappelijk onderzoek naar de invloed van het lezen, ed. Frank Hakemulder, 160-182. Amsterdam: Stichting Lezen Reeks.

Lanchester, John. 2013. The Snowden files: Why the British public should be worried about GCHQ. The Guardian, October 3. http://www.theguardian.com/world/2013/oct/03/edwardsnowden-files-john-lanchester.

Libet, Benjamin, Curtis A. Gleason, Elwood W. Wright, and Dennis K. Pearl. 1983. Time of conscious intention to act in relation to onset of cerebral activity (readiness-potential). The unconscious initiation of a freely voluntary act. Brain 106: 623-642.

Marchewka, Artur, and Anna Nowicka. 2007. Emotionally negative stimuli are resistant to repetition priming. Acta Neurobiologiae 67: 83-92.

Martindale, Colin. 1990. The clockwork muse: The predictability of artistic change. New York: Basic Books.

Massey, Irving. 2009. The neural imagination: Aesthetic and neuroscientific approaches to the arts. Austin: University of Texas Press.

Miall, David S. 2001. Sounds of contrast: An empirical approach to phonemic iconicity. Poetics 29: $55-70$.

Miall, David S. 2012. How does it feel? Attending to the unreliable narrator. Fictions Special Issue: Plots of the Mind-Narrative and Cognitive Sciences 11: 41-57.

Miall, David S., and Don Kuiken. 1999. What is literariness? Three components of literary reading. Discourse Processes 28: 121-138.

O'Faoláin, Seán. 1980. The trout. In The collected stories of Seán O'Faoláin, 383-386. London: Constable.

Posner, Michael I., and Gregory J. DiGirolamo. 2000. Cognitive neuroscience: Origins and promise. Psychological Bulletin 126: 873-889.

Rellecke, Julian, Werner Sommer, and Annekathrin Schacht. 2012. Does processing of emotional facial expressions depend on intention? Time-resolved evidence from event-related brain potentials. Biological Psychology 90: 23-32.

Richardson, Alan. 2001. British romanticism and the science of the mind. Cambridge: Cambridge University Press.

Rigoni, Davide, Marcel Brass, and Giuseppe Sartori. 2010. Post-action determinants of the reported time of conscious intentions. Frontiers in Human Neuroscience 4: 38.

Ruskin, John. 1897. Modern painters. London: George Allen.

Schupp, Harald T., Jessica Stockburger, Maurizio Codispoti, Markus Junghofer, Almut I. Weike, and Alfons O. Hamm. 2006. Stimulus novelty and emotion perception: The near absence of habituation in the visual cortex. NeuroReport 17: 365-369.

Shelley, Percy Bysshe. 1988. A defence of poetry. In Shelley's prose, ed. David Lee Clark, 275297. London: Fourth Estate.

Shklovsky, Viktor. 1917/1965. Art as technique. In Russian formalist criticism: Four essays, ed. and trans. L.T. Lemon and M.J. Reis, 3-24. Lincoln: University of Nebraska Press. 
Sloboda, John A. 1991. Music structure and emotional response: Some empirical findings. Psychology of Music 19: 110-120.

Smith, Greg. 2003. Film structure and the emotion system. Cambridge: Cambridge University Press.

Wang, An.Li., André Mouraux, M. Liang, and Gian Domenico Iannetti. 2008. The enhancement of the N1 wave elicited by sensory stimuli presented at very short inter-stimulus intervals is a general feature across sensory systems. PloS One 3(12): e3929. doi:10.1371/journal.pone. 0003929.

Woolf, Virginia. 1937/2009. The years, ed. Hermione Lee. Oxford: Oxford University Press.

Wordsworth, William. 1979. The prelude, 1799, 1805, 1850, ed. Jonathan Wordsworth, M.H. Abrams, and Stephen Gill. New York: Norton.

Zwaan, Rolf A. 1993. Aspects of literary comprehension. Amsterdam/Philadelphia: John Benjamins. 